\title{
Qual o lugar da maternidade lésbica e bissexual na escola?
}

\author{
Luciene Celina Cristina Mochi ${ }^{1}$; Ana Rosa Costa Picanço Moreira²
}

\section{Resumo}

A existência das famílias formadas por mulheres lésbicas e bissexuais desafia a heterossexualidade compulsória e, por conseguinte, questiona o modelo de família tradicionalmente reproduzido pelas instituições sociais, especialmente a escola. Essa composição familiar binária que conserva como matriz de família ideal aquela composta pelo pai, mãe e filhas/os, parece perseverar ao lado de mudanças e desmembramentos ocorridos nas configurações familiares desde a década de 1970. Nesta perspectiva, é no contexto escolar que a chegada das crianças filhas de mães lésbicas e bissexuais rompe com a lógica binária promovendo outras possibilidades de conceber e viver em famílias. Ao considerar este debate, o presente artigo tem como objetivo problematizar o lugar que as mães lésbicas e bissexuais ocupam no contexto escolar. Para tanto, organizou-se uma pesquisa bibliográfica pautada nas Teorias Feministas e nos estudos sobre as Relações de Gênero. Nas considerações finais, apresentam-se justificativas que contribuem com investigações científicas interessadas na perspectiva das relações entre a escola e as famílias.

Palavras-chave: maternidades lésbicas e bissexuais; feminismos; educação escolar. 


\section{Abstract}

The existence of families formed by lesbian and bisexual women challenges compulsory heterosexuality and therefore questions the model traditionally reproduced by social institutions, especially the school. This binary family composition that preserves as a matrix ideal family composed of the father, mother and daughters, seems to persevere alongside changes and dismemberments occurred in family settings since the 1970s. In this perspective, it is in the school context that the arrival of children daughters of lesbian and bisexual mothers breaks with binary logic promoting other possibilities of conceiving and living in families. When considering this debate, this article aims to problematize the place of lesbian and bisexual mothers occupy in the school context. To this end, a bibliographical research was organized based on the Feminist Theories and studies on gender relations. In the final considerations, justifications are presented that contribute to scientific research interested in the perspective of relations between school and families.

Keywords: lesbian and bisexual motherhood; feminisms; school education.

\section{Introdução}

O modelo de família tradicionalmente reproduzido pelas instituições sociais, sobretudo a escola, baseia-se na associação entre "aliança-filiação" e "sexualidade-reprodução" (CÔTÉ, 2009). Essas estruturas associativas são utilizadas para definir a família nuclear heterossexual entendida pela composição do casal (homem heterossexual e mulher heterossexual) e as/os filhas/os advindas/os dessa união. Porém, desde a década de 1970, com a Lei do Divórcio, o controle da reprodução e a emergência das configurações familiares plurais, vemos o desmembramento e as transformações sobre novos significados de conceber e viver em famílias. Passamos da ideia de um modelo único de família para uma pluralidade nas configurações 
família gestado por meio da "heterossexualidade compulsória"3.

Assim, o presente artigo tem como objetivo problematizar o lugar que as famílias formadas por mães lésbicas e bissexuais ocupam nas escolas de Educação Infantil e Ensino Fundamental. Essa discussão está pautada nas teorias feministas (CÔTÉ, 2009; HIRATA, 2014; RICH, 1980; 2010), e tem o propósito de tecer considerações a respeito da educação escolar em relação às percepções sobre essas famílias. Entendemos que as mães que são lésbicas e/ou bissexuais e que possuem filhas/os frequentando a Educação Infantil e o Ensino Fundamental podem estabelecer no contexto escolar, possibilidades para a socialização e interiorização de atitudes respeitosas e a garantia de direitos democráticos. Por meio das relações sociais existentes entre a escola e as famílias de suas/eus alunas/os somos capazes de sublinhar as possíveis influências cotidianas vivenciadas pelas crianças que não possuem a família nuclear como base familiar. Uma vez que a família denominada "padrão" e contornada pela heterossexualidade e fixada como única (CÔTÉ, 2009), reproduzida pelas instituições escolares, pode agregar desigualdades de gênero e colocar as crianças que são filhas/os de uniões de mulheres lésbicas e/ou bissexuais em um 'não lugar', gerando conflitos discriminatórios e variados tipos de constrangimentos, entre eles a invisibilidade de suas famílias e, com ela, o sentimento de não pertencimento.

Destacamos que é no contexto escolar que a existência das crianças filhas e filhos de mães lésbicas e/ou bissexuais, podem promover outras concepções da relação família e escola, para o efetivo exercício da democracia como direito e, garantia à cidadania das crianças filhas/os de mulheres lésbicas e/ou bissexuais, reivindicando a legitimidade desta configuração familiar. Portanto, a invisibilidade e 
homoparentalidade e, em especial neste texto, a lesboparentalidade ${ }^{4}$, põe em xeque a aplicação e efetivação das políticas educacionais que se colocam a serviço da proteção e dos cuidados para as crianças no contexto escolar. Por exemplo, a Lei de Diretrizes e Bases da Educação Nacional (BRASIL, 1996, p. 23), no artigo 32, parágrafo IV prevê “o fortalecimento dos vínculos de família, dos laços de solidariedade humana e de tolerância recíproca em que se assenta a vida social". Logo, é dever da escola estabelecer e fortalecer o vínculo com as famílias, assim como a consolidação de atitudes que demonstrem os laços afetivos/sociais como um direito.

Metodologicamente, este artigo foi organizado em dois tópicos de desenvolvimento. No primeiro, debatemos sobre a importância das teorias feministas para estabelecermos um lugar de visibilidade para as mães que são lésbicas e/ou bissexuais e suas/eus filhas/os na educação escolar. Além disso, a partir das contribuições de Rich (1980; 2010), argumentamos a respeito da naturalização da maternidade para as mulheres ao lado do conceito de "heterossexualidade compulsória". No segundo, discutimos a existência das maternidades lésbicas e/ou bissexuais na escola como possiblidades de superação das diferenças como assimetria, contextualizando que as crianças, filhas e filhos de mães que são lésbicas e/ou bissexuais, podem constituir significativo aprendizado a respeito da democracia e equidade na escola.

Nas considerações finais, apontamos justificativas que contribuem para pensarmos o lugar das maternidades lésbicas e bissexuais na escola como instrumento de existência e resistência. A presença das mães $\mathrm{LésBi}^{5}$ e suas/eus filhas/os nos contextos escolares

4 Utilizamos neste artigo o termo lesboparentalidade para nos referirmos à configuração 
patriarcal, suas existências e de suas famílias, questionam as certezas sobre o modelo único de família, colaborando assim, para uma educação mais justa e consequentemente democrática.

\section{Feminismos, maternidades lésbicas e educação escolar}

Percebo a experiência lésbica a ser, tal como a maternidade, uma experiência profundamente feminina, com opressões, significados e potencialidades particulares, que não podemos compreender quando nós a agrupamos simplesmente com outras existências sexualmente estigmatizadas (RICH, 2010, p. 37).

Encontramos na epígrafe que inaugura esta seção a reflexão de Adrienne Rich de que a experiência da maternidade lésbica é atravessada por significados e opressões singulares, sendo importante compreender as imbricações das variadas violências que marcam os corpos e as subjetividades das mulheres, sobretudo quando se trata da naturalização da maternidade. Desse modo, parece-nos interessante que a maternidade LésBi seja compreendida a partir dos diferentes feminismos que tradicionalmente debatem a maternidade como categoria essencial para pensarmos na reprodução social do seu significado. As dinâmicas vividas e experenciadas pelas mães LésBi e suas/eus filhas/os na escola podem auxiliar nos estudos do campo da educação que debatem a normalização e a regulação do governo das mulheres e das crianças, exercido pela sociedade patriarcal (pais, judiciário, médicos, especialistas, religiosos, políticos). A escola como instituição social desempenha, por meio dos processos educativos, a reprodução de normas heterossexistas que garantem a manutenção 
papel político que os estudos sobre homoparentalidades e educação adquiriram nos últimos anos, sobretudo os estudos da maternidade, que pautam suas raízes históricas refazendo os elementos ideológicos que o próprio termo 'maternidade' possui. $\mathrm{O}$ termo "homoparentalidade", cunhado no ano de 1996, na França, pela Associação de Pais e Futuros Pais Gays e Lésbicas (APGL), teve por objetivo nomear "[...] a situação na qual pelo menos um adulto que se autodesigna homossexual é (ou pretende ser) pai ou mãe de, no mínimo, uma criança" (ZAMBRANO, Elizabeth et al, 2006, p. 10). Esta terminologia, porém, não tem se mostrado suficiente para atender a todas e todos os arranjos familiares uma vez que as famílias são compostas por múltiplas conjugalidades. As configurações familiares compostas pelas mães LésBi e suas/eus filhas/os requerem propostas que ajudem a discutir os diferentes atravessamentos que o machismo e a sociedade patriarcal impõem às mulheres.

A feminista Elixabete Imaz (2016) assinala que as questões principais que conseguimos levantar a respeito das construções preexistentes sobre as limitações que o modelo patriarcal supõe para as mulheres é o de papéis previamente estabelecidos, como por exemplo, ser a mulher o eixo da família, responsável pela condução única da segurança das/os filhas/os. Desse modo, a autora faz importante consideração sobre as famílias contemporâneas e o lugar da mulher nessas famílias:

Assim, as novas formas familiares estão intimamente ligadas a como as mulheres, a partir de suas novas e diversas situações sociais, enfrentam e exercitam a maternidade. A transformação do lugar das mulheres na sociedade (sua maior participação na esfera pública, o desenvolvimento de uma dimensão extradoméstica) e também as mudanças que 
tardia, as mães trabalhadoras que preferem continuar trabalhando, a aceitação social de novas formas de família, como mães solteiras por opção ou mães em relacionamento lésbico (IMAZ, 2016, p. 489, tradução nossa) ${ }^{6}$.

Discussões sobre a relação das mães LésBi com a escola de suas/eus filhas/os podem possibilitar debates diversos a respeito do modelo de família estabelecido pelas instituições sociais. Este tema é certo, passa na tangente de boa parte da literatura feminista e dos Estudos de Gênero, unindo diferentes debates sobre corporalidade, sexo, desejo, normas de gênero, sexualidades e a naturalização da maternidade. Nesse sentido, os estudos feministas proporcionam avanço teórico capaz de auxiliar a compreender a importância da existência das crianças filhas e filhos de mães LésBi na escola. Uma vez que os feminismos tensionam e provocam deslocamentos nas relações de gênero para além das hierarquizações dos eixos dos marcadores sociais, eles contribuem para o diálogo no âmbito das relações familiares, animadas pelo afeto e pelo desenvolvimento humano/educacional/social das/os estudantes da Educação Infantil e Ensino Fundamental.

Portanto, as crianças filhas e filhos de mães lésbicas e/ou bissexuais presentes no contexto escolar são ricas possibilidades de reconstrução no interior da escola, dos seus modos de socialização e de democracia, no desenvolvimento de atitudes concretas para uma educação que seja capaz de atuar para além das desigualdades polarizadas, livre do machismo, sexismo e LGBTfobias . Do mesmo

6 "Es así que las nuevas formas familiares están intimamente vinculadas a cómo las mujeres, desde sus nuevas y diversas situaciones sociales, encaran y ejercen la maternidad. La transformación del lugar de las mujeres en la sociedad (su mayor participación en lo público, el desarrollo de una dimensión extradoméstica) y también 
construções históricas e hierárquicas que foram fundamentadas na ideia de conjugalidade burguesa, que estabeleceram normas e vigília na vida familiar, sobretudo para as mulheres. O debate sobre família é operado por controles que estabelecem algumas formas de conjugações familiares legítimas e valorizadas e, consequentemente, formas não aceitáveis e passíveis de discriminação e estigmas, ficando suscetíveis ao silêncio, privações e variadas imbricações de vulnerabilidade. A esse respeito, Flávia Biroli (2018) discorre:

Isso implica não apenas reconhecimento social desigual, mas também acesso desigual a direitos e recursos materiais. Desde a eletividade para políticas públicas e financiamentos de moradia até o acesso comum a planos privados de seguridade e saúde, a adoção de crianças e a transmissão da herança, há todo um espectro de questões diretamente implicadas nas normas e nos valores que definem o que é reconhecido como família (BIROLI, 2018, p. 92).

A autora chama a atenção para o fato de que apesar de terem acontecido mudanças e transformações ao longo da história, o peso da vida em família e da divisão sexual do trabalho, ainda é destinado com maior desvantagem às mulheres nas relações sociais modernas. Seja na convivência íntima, ou na esfera pública, a existência de práticas de realizações desiguais entre mulheres e homens persistem nas tarefas domésticas, no cuidado e gerenciamento da casa, das/os filhas/os, na distribuição de responsabilidades, atribuídas de maneira desigual para as mulheres.

As famílias são constituídas e estabelecidas pelas relações de afeto e processos sociais. Desta forma, elas encontram-se interligadas na ação existente entre o que é institucional, material e representativo (BIROLI, 2018). Apesar de corresponderem a uma infinidade de 
parentalidade e de coabitação" (BIROLI, 2018, p. 91).

Portanto, a parentalidade e a constituição familiar entre pessoas do mesmo sexo podem exercer efeito desestabilizador do conceito de família nuclear habitualmente reproduzido e evidenciado como modelo único de família. O que pode ser analisado nas interconexões existentes no campo social e cultural que possuem leis e políticas públicas que estruturam a família nuclear. De seu próprio modo, as relações familiares são gestadas por estas instituições sociais e entre elas, a escola parece ser um campo que favorece a (re)produção de modelos e comportamentos a serem seguidos sob a égide de serem "comportamentos socialmente aceitos", sobretudo e, em particular, o da família constituída por um pai, uma mãe e suas/eus filhas/os, apoiando na heterossexualidade, a norma padrão de se constituir família.

A maternidade colocada para as mulheres como destino natural em nossa sociedade patriarcal, já não parece possuir o mesmo sentido naturalizado para aquelas que são lésbicas, bissexuais e transexuais, podendo ser lidas como maternidades desviantes, fora da norma e assim em um "não lugar". Ao vincular a maternidade como destino naturalizado para as mulheres e não socialmente adotado também como política e existência - pública e privada - das mães LésBi, vincula-se com o princípio de autorização seletiva, que distingue com base aos estigmas binários e da heterossexualidade compulsória, as maternidades que são acionadas como legítimas e não legítimas. Portanto, a maternidade LésBi suscita ambivalências pois, se por um lado há as construções sociais sobre a maternidade e com ela as atribuições do cuidado como predicado feminino, por outro, há designação da heterossexualidade imposta às mulheres, sobretudo para as que são mães.

A naturalização da maternidade e a pressuposição da 
bissexual no contexto escolar concorrem para uma ação política e afirmativa de cidadania. Nas palavras da socióloga francesa Isabel Côté (2009), as maternidades lésbicas deslocam o modelo único e naturalizado de família, "As famílias lesboparentais aprofundaram essa lógica dissociativa refutando a dualidade sexual como base da reprodução e reivindicando sua legitimidade" (CÔTÉ, 2009, p. 25).

A autora (2009) discorre sobre uma pesquisa que desenvolveu no Quebec com mães lésbicas cujo objetivo foi compreender até que ponto as famílias lesboparentais são diferentes das conjugações familiares nucleares. A socióloga concluiu que se há subversão das normas, há também conformação, pois, embora as famílias lesboparentais desafiem por sua própria existência a estrutura nuclear e padronizada das relações de gênero e, consequentemente, da família, também conformam a norma. $\mathrm{O}$ dia a dia das crianças nessa família, o cotidiano escolar, a responsabilidade com os cuidados e as representações de afeto na unidade familiar, o núcleo que fortalece o casal e a inscrição da família dentro dos laços intergeracionais desmistificam a maternidade lésbica como não legítima.

A homossexualidade é denunciada na praça pública por algumas pessoas como uma caixa de Pandora desafiando a instituição familiar, apresentada como a base da civilização ocidental e cristã. No entanto, as famílias homoparentais são tão subversivas? Nossa análise com mães lésbicas [...] sugere que, se há subversão, há também reprodução de normas (CÔTÉ, 2009, p. 25, tradução nossa) ${ }^{7}$.

Ao considerarmos esse amplo debate em torno da visão patriarcal heteronormativa da família, contamos com a contribuição de 
maternidade, circundada pelas opressões, mas também, pelos significados e especificidades que não podem ser compreendidos de modo agrupado com outras existências que são estigmatizados. Saber a diferença entre o que é ser "mãe" e o termo usualmente utilizado como "os pais" é compreender "a realidade particular e significativa de ser uma mãe [...] contornos que precisamos discernir, que são de valor crucial para o feminismo e para a liberdade das mulheres como um grupo" (RICH, 2010, p. 37). A heterossexualidade examinada como uma instituição política nos faz perceber que o poder é retirado das mulheres. Ao examinar a heterossexualidade dada como natural, os questionamentos aos mecanismos de opressão são passíveis de serem transformados. De acordo com Rich,

\begin{abstract}
As instituições nas quais as mulheres são tradicionalmente controladas - a maternidade em contexto patriarcal, a exploração econômica, a família nuclear, a heterossexualidade compulsória - tem sido fortalecidas através da legislação, como um fiat religioso, pelas imagens midiáticas e por esforços de censura (RICH, 2010, p.19, grifos nosso).
\end{abstract}

Algumas famílias são reconhecidas social e institucionalmente, ao passo que outras necessitam explicar suas configurações, lutar pela garantia de direitos, de existência e políticas públicas de reconhecimento. Isto parece ser uma contínua reprodução do casal heterossexual (homem e mulher) na base da definição do que vem a ser família, tendo o "não lugar" reservado para as mães lésbicas e bissexuais. Talvez essa diferença modular aconteça porque a autonomia e a igualdade das mulheres podem ameaçar a estrutura patriarcal. Portanto, discutir maternidade LésBi no campo da educação é um caminho para o estabelecimento do debate das múltiplas formas de ser e estar em família. É na escola que a existência das famílias LésBi e 
Em uma festa ou reunião de pais na escola, essas duas mães podem vir, mas não podem se abraçar ou pegar na mão. Se elas se comportarem como duas amigas, ai pode. Maria Lacerda, professora, 37 anos. (MOCHI, 2019, p. 57).

O excerto enunciado no início deste tópico é parte do relato de uma professora entrevistada durante pesquisa de mestrado realizada com pedagogas e professoras que atuam no Ensino Fundamental - séries iniciais, em uma cidade do Paraná, no ano de 2016. Perguntada à professora se a escola está preparada para receber as mães lésbicas e bissexuais nas reuniões escolares, ela narra o que parece ser, na opinião dela, o comportamento "adequado" para as mães LésBi frequentarem as atividades escolares.

A narrativa da professora aponta para o quanto a educação pode aprender com as conjugalidades lésbicas e/ou bissexuais no interior do espaço escolar. Existe um interdito anunciado para as relações eróticoafetivas entre mulheres: o enlevo da amizade feminina e que não pode ser associado ao desejo e relacionamento erótico-afetivo, existente nas relações humanas e, o que não é diferente, para as mulheres lésbicas, bissexuais e transexuais. A presença do corpo dessas mulheres nos corredores da escola tem valor político que por si só são capazes de romper com o silêncio e mistério que fortalecem a manutenção do poder. Ademais, as crianças que possuem mães LésBi já estão nos espaços escolares o que nos intenta a dizer que não há necessidade (nem tempo) para preparação, mas, sobretudo, urgência em se fazer visível esta e todas as pluralidades familiares existentes na escola.

A expressão encontrada pela professora na interdição/condição 
entre mulheres. A percepção que pode ser encontrada nesses discursos parece ser a mesma ferramenta utilizada no uso da conexão entre maternidade e sexualidade como controle da capacidade autônoma das mulheres.

$O$ vínculo existente entre mulheres não necessariamente lésbicas e/ou bissexuais é o que considerou Adrienne Rich (2010) como "impulso politicamente ativado". De acordo com a autora (2010), precisamos construir significados a partir da profundidade, amplitude e identificação do vínculo existente entre mulheres, o que permanece de maneira constante, apesar da omissão, por meio da heterossexualidade compulsória, um impulso politicamente ativado para além da autorização da vida das pessoas. Os vínculos e a identificação entre mulheres como acionamentos ativos para a resistência feminina transformam a experiência lésbica percebida por meio da via da heterossexualidade em uma escala flutuante que parte do sentimento de negação ao desviante ou a ser simplesmente apresentada como invisível. De acordo com Rich,

Qualquer teoria ou criação cultural/política que trate a existência lésbica como um fenômeno marginal ou menos "natural", como mera "preferência sexual", como uma imagem espelhada de uma relação heterossexual ou de uma relação homossexual masculina seria, portanto, profundamente frágil, independente de qualquer contribuição que ainda tenha (RICH, 2010, p. 22).

Entretanto, no mesmo momento em que a escola contribui para a fixidez das interdições das relações de gênero, a existência das conjugalidades compostas por duas mulheres no interior da escola "afrouxa os nós" e abrem caminho para a instituição escolar que pode aprender com a diferença e não com a manutenção dos eixos que 
“[...] a intersecção é de geometria variável, podendo incluir, além das relações sociais de gênero, de classe e de raça, outras relações sociais, como a de sexualidade, de idade, de religião etc" (HIRATA, 2014, p. 66).

Do mesmo modo, as práticas escolares atuam no sentido de "adestrar" os corpos e submeter meninas e meninos a padrões diferenciados, resultando em assimetrias e desigualdades. Ao regular os corpos e a afetividade, a escola (re)produz o controle das experiências familiares. Questionar qual é o lugar das maternidades lésbicas na escola é importante para suscitarmos deslocamentos necessários na maneira binária e naturalizada que a escola desenvolve cotidianamente, como na definição ideal e modular de família. Se não considerarmos o debate de gênero e as abordagens feministas como ferramentas potentes do ponto de vista da democracia, mais distante ficará o horizonte que se espera para a superação das desigualdades e variadas violências nos espaços escolares.

A existência das conjugações familiares formadas por mães lésbicas e/ou bissexuais na escola amplia o desenvolvimento de novas práticas emancipatórias e democráticas, estabelecendo no interior (e também do lado de fora) destas instituições, espaços plurais e acolhedores para todas as crianças, pois aprender a lidar com as diferenças se faz na ação do cotidiano escolar através do acolhimento e da visibilidade das famílias que cuidam e protegem suas crianças.

A escola, entendida como instituição social, caracteriza-se como espaço imperioso na condução das relações de gênero, e, por este prisma, o ambiente escolar pode contribuir sobremaneira para ações democráticas baseadas no respeito e no reconhecimento das múltiplas formas de se constituir famílias. Reconhecemos a escola como importante ambiente socializador que, constituído de signos de 
contexto escolar pode significar um aprendizado para todo o corpo docente e, também, para todas as famílias das crianças que frequentam esse espaço. Uma vez pautada na pluralidade, as famílias LésBi podem atualizar as relações sociais hegemônicas balizadas pela diferença lida pelo viés da desigualdade. Contudo, só será possível garantir uma escola com práticas democráticas se conseguirmos construir também respostas consideradas apropriadas para o estabelecimento de mecanismos educativos que não silenciem a existência dessas maternidades como legítimas. Para isso, faz-se necessário acionar a perspectiva feminista de modo ativamente militante e também acadêmico, reconhecendo que a heterossexualidade "[...] pode não ser uma "preferência", mas algo que tem sido imposto, administrado, organizado, propagandeado e mantido por força [...]" (RICH, 2010, p. $34)$.

Assim, o contexto escolar figura como um ambiente significativo para que o aprendizado da diferença aconteça. Considerando o espaço escolar como lugar possível para o debate das relações de gênero, da adoção da diferença como valor plural, possibilitando o acesso e a permanência das/os estudantes que advém de variados arranjos familiares. Mas para que esse aprendizado vigore, faz-se necessário que a escola esteja preocupada com a qualidade do atendimento educacional, do envolvimento igualitário e das condições necessárias para o impulso politicamente ativo de meninas, meninos e suas mães.

Há de se ressaltar que o grande desafio contemporâneo da educação escolar está em saber lidar com as diferenças pessoais, individuais, familiares, culturais e sociais, promovendo com coragem a "libertação do pensamento, a exploração de novos caminhos, a dissolução de outro grande silêncio, uma nova claridade nas relações intornaccopic" (RICH 2010 n 35) 
“- articular-se com as famílias e a comunidade, criando processos de integração da sociedade com a escola" (BRASIL, 1996, p. 14).

Considerando as diferentes relações sociais que pautadas em ações afirmativas e, por conseguinte, respeitosas para todas as famílias dentro do espaço escolar, conseguiremos também, diminuir a reprodução das desigualdades sociais, que baseiam seu alicerce na injusta relação entre grupos que são dominantes e os grupos que são dominados. Neste sentido, Helena Hirata (2014) contribui para pensarmos sobre o modo como as mulheres sempre ocuparam um lugar na história que foi determinado do ponto de vista das relações de poder com intersecções que ajustam os nós opressores nas relações assimétricas entre os gêneros.

Nessa perspectiva, a ideia de um ponto de vista próprio à experiência e ao lugar que as mulheres ocupam cede lugar à ideia de um ponto de vista próprio à experiência da conjunção das relações de poder de sexo, de raça, de classe, o que torna ainda mais complexa a noção mesma de "conhecimento situado", pois a posição de poder nas relações de classe e de sexo, ou nas relações de raça e de sexo, por exemplo, podem ser dissimétricas (HIRATA, 2014, p. 61).

Embora reconheçamos que não é possível eliminar da escola todas as formas de violências, discriminações e constrangimentos, sabemos que a luta dos diferentes feminismos será sempre uma lição possível a ser empenhada na escola, por parte das/os gestoras/es e por parte de todo corpo docente. Esse exercício precisa ser cotidiano para que não haja espaço dentro e fora das salas de aula que propiciem as práticas discriminatórias contra as mulheres e crianças, aumento da discriminação e dos preconceitos contra mulheres, principalmente para 


\section{Considerações Finais}

A existência das maternidades lésbicas e bissexuais na escola colabora para o rompimento dos processos escolares como mecanismos reprodutores de desigualdades das categorias de gênero, classe, raça e orientação sexual. Ao desafiarem a heterossexualidade como norma, essas famílias tencionam a estrutura patriarcal e questionam as velhas certezas sobre o modelo único de família, tradicionalmente comemorado pela instituição escolar.

Os diferentes feminismos vigoram como múltiplas vias para o enfrentamento e superação das imbricações opressoras desenvolvidas pelo poder patriarcal que legitima algumas famílias em detrimento de outras. A existência das crianças filhas de mães lésbicas e/ou bissexuais produzem na escola o efeito denunciador - mesmo sem ser essa a intenção principal - estratégias que podem ser apreendidas por todas as outras crianças e suas famílias, sobre respeito, democracia e Direitos Humanos, contribuindo significativamente para a elaboração e intervenção nas práticas educativas.

As considerações tecidas neste artigo colaboram na perspectiva de apontar a chegada das crianças filhas de mães lésbicas e/ou bissexuais no contexto escolar e, com essa chegada, a lógica binária das relações de gênero é rompida. Esse fato pode favorecer novas aprendizagens sobre a ideia de família por parte da escola e de toda comunidade escolar. Um convite a conviver [e aprender] novas formas plurais de conceber e viver em família.

Por fim, parece-nos importante asseverarmos que a concepção feminista de educação colabora com um novo modelo pedagógico capaz de superar as relações patriarcais de dominação, podendo se configurar 
pessoas, especialmente para as mulheres e crianças. Afinal, como já descrito anteriormente, as mães LésBi fogem do aprisionamento da naturalização da maternidade, uma vez que mudam o jogo do controle social organizado pela sociedade patriarcal e, sendo assim, é também um modo de resistir e (re)existir às tentativas atuais de retrocessos, tanto para as questões das relações de gênero e sexualidade, quanto para as garantias de políticas educacionais mais equânimes.

\section{Referências}

AMORIM, Anna Carolina Horstmann. Novas tecnologias reprodutivas e maternidades lésbicas no Brasil e na França: conexões entre parentesco, tecnologias e política. 2018. 451f. Tese (Doutorado em Antropologia Social) -Universidade Federal de Santa Catarina, Florianópolis, 2018.

BIROLI, Flávia. Gênero e desigualdades: os limites da democracia no Brasil. 1. ed. São Paulo: Boitempo, 2018.

BRASIL. Ministério da Educação. LDB: Lei de Diretrizes e Bases da Educação Nacional. Brasília: Senado Federal, Coordenação de Edições Técnicas, 2017. 58 p. Disponível em: http://www2.senado.leg.br/bdsf/bitstream/handle/id/529732/lei _de_diretrizes_e_bases_1ed.pdf Acesso: 03 jun. 2018.

CÔTÉ, Isabel. La lesboparentalité: subversion ou reproduction des normes? Recherches féministes, n. 22, v. 2, p. 25-38, 2009. doi:10.7202/039208ar.

Disponível: https:/ / www.erudit.org/fr/revues/rf/2009-v22-n2-rf3635. Acesso em: 04 maio 2020.

HIRATA, Helena. Gênero, classe e raça Interseccionalidade e consubstancialidade das relações sociais. Tempo Social, São Paulo, v. 26, n. 1, p. 61-73, jun. 2014. ISSN 1809-4554. Disponível em: http://www.revistas.usp.br/ts/article/view/84979/87743. Acesso 
modelos maternales contemporáneos. Revista Estudos Feministas,

Florianópolis, v. 24, n. 2, p. 485-497, ago. 2016. Disponível em: http:/ / www.scielo.br/scielo.php?script=sci_arttext\&pid=S0104026X201600 0200485\&lng=en\&nrm=iso. Acesso em: 13 ago. 2020.

MOCHI, Luciene Celina Cristina. Afinal, do que é feita uma família? Maternidades lésbicas na escola. Rio de Janeiro, RJ: Metanóia, 2019.

$\mathrm{RICH}$, Adrienne. Compulsory heterosexuality. Signs, The University of Chicago Press, v. 5, n. 4, p. 631-660, Sumer, 1980.

RICH, Adrienne. Heterossexualidade compulsória e existência lésbica. Compulsory Heterosexuality and Lesbian Existence. Tradução: Carlos Guilherme do Valle. Rev. Bagoas. Florianópolis, v. 4, n. 5, p. 17-44, 2010. Disponível:

https:/ / periodicos.ufrn.br/bagoas/issue/view/191/showToc. Acesso em: 29 jun. 2018.

SILVA, Zuleide Paiva da. "Sapatão Não É Bagunça": Estudo das Organizações Lésbicas da Bahia. 2016. 383 f. Tese (Doutorado em Multi-Institucional e Multidisciplinar em Difusão do Conhecimento) - Universidade Federal da Bahia, Salvador, 2016.

ZAMBRANO, Elizabeth; LOREA, Roberto; MYLIUS, Leandra; MEINERZ, Nádia; BORGES, Priscila. O direito à homoparentalidade: Cartilha sobre as famílias constituídas por pais homossexuais. Porto Alegre: Instituto de Acesso à Justiça, 2006. 